\title{
Folkcomunicação nas transformações tecnológicas e midiáticas contemporâneas
}

\section{Folkcommunication in contemporary technological and mediatic transformations

\author{
Folkcomunicación en las transformaciones tecnológicas y mediáticas \\ contemporâneas
}

\author{
Yuji GUSHIKEN ${ }^{1}$
}

\begin{abstract}
Resumo
A emergência e a afirmação da folkcomunicação como perspectiva teórica na pesquisa em Comunicação atenta para reinvenção de práticas midiáticas e comunicacionais no âmbito das manifestações tradicionais e da cultura popular brasileira. A singularidade da folkcomunicação é sua configuração teórica numa insistente situação de tática das manifestações tradicionais e populares hoje enredadas pelas transformações tecnológicas e midiáticas. Esta condição difusa promovida pelas convergências do popular com o tecnológico equivale, na experiência da vida urbana, às aproximações entre as insistentes precariedades da vida social e o consumo de novas tecnologias. No plano metodológico, o artigo se desenvolve com base em pesquisa bibliográfica, na perspectiva maior da comunicação como cultura, num diálogo com as ciências sociais.
\end{abstract}

Palavras-chave: Folkcomunicação. Transformações tecnológicas. Mídias digitais. Capitalismo tardio.

\begin{abstract}
The emergency and affirmation of folkcommunication as a theoretical perspective in the communication research attempt to the reinvention of media and communication practices in the scope of traditional manifestations and Brazilian popular culture. The singularity of folkcommunication is its theoretical configuration in an insistent tactic situation from traditional and popular manifestations nowadays evolved by technological and media transformations. This diffuse condition promoted by the convergences of the popular and the technological equals to, in urban life experience, the proximities between

\footnotetext{
${ }^{1}$ Professor do Departamento de Comunicação Social e do Programa de Pós-Graduação em Estudos de Cultura Contemporânea da Universidade Federal de Mato Grosso (PPGECCO-UFMT/Cuiabá). Líder do Grupo de Pesquisa em Comunicação e Cidade (Citicom-UFMT/CNPq). Doutor em Comunicação e Cultura pela Universidade Federal do Rio de Janeiro (ECO-UFRJ). Pós-doutorado no Programa de PósGraduação em Comunicação da Universidade Federal do Ceará (PPGCOM-UFC) (2020-2021). E-mail: yug@uol.com.br. ORCID: 0000-0002-6620-3375.
} 
the insistent precariousness of social life and the use of new technologies. In a methodological plan, this article is developed by taking the bibliographic research as a basis, in a larger perspective of communication as culture, in a dialogue with social sciences.

Keywords: Folkcommunication. Technological transformations. Digital media. Late capitalism.

\section{Resumen}

El surgimiento y afirmación de la comunicación popular como perspectiva teórica en la investigación en Comunicación atenta a la reinvención de los medios y prácticas comunicacionales en el ámbito de las manifestaciones tradicionales y la cultura popular brasileña. La singularidad de la comunicación popular es su configuración teórica en una situación táctica insistente de las manifestaciones tradicionales y populares que actualmente se encuentran enredadas por las transformaciones tecnológicas y mediáticas. Esta condición difusa promovida por la convergencia de lo popular con lo tecnológico equivale, en la experiencia de la vida urbana, a las aproximaciones entre la precariedad insistente de la vida social y el consumo de nuevas tecnologías. A nivel metodológico, el artículo se desarrolla a partir de la investigación bibliográfica, en la perspectiva más amplia de la comunicación como cultura, en diálogo con las ciencias sociales.

Palabras clave: Folkcomunicación. Transformaciones tecnológicas. Medios digitales. Capitalismo tardío.

\section{Introdução}

A folkcomunicação, perspectiva teórica desenvolvida pelo jornalista, professor e pesquisador brasileiro Luiz Beltrão, foi concebida historicamente nas Ciências da Comunicação, refletindo a condição de ampla desigualdade econômica e intensas diferenciações culturais existentes no Brasil. Beltrão concebe e desenvolve a perspectiva teórica a partir do momento em que interpreta, na coexistência de mundos simbólicos distintos no vasto território nacional, o modo como as camadas socialmente marginalizadas inventam e desenvolvem processos comunicacionais. Para amplas faixas da população brasileira, os processos cognitivos e os múltiplos manuseios das memórias coletivas, no âmbito do folclore e das culturas populares, tornaram-se condição epistêmica e motivo de produção simbólica e, portanto, de processos de produção de sentido (BELTRÃO, 1980; 2001; 2004).

As dinâmicas comunicacionais nas práticas culturais constituem empiricamente e caracterizam teoricamente a folkcomunicação como perspectiva historicamente 


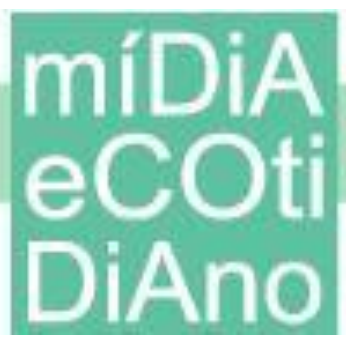

construída para estudos do fenômeno comunicacional na conflituosa e heterogênea experiência de modernização brasileira. Na produção dessa perspectiva teórica, interessam a observação e a interpretação dos processos de produção de sentido nas práticas do folclore e sua transformação no âmbito das culturas populares, e, no mais das vezes, no popular urbano. As transformações culturais, no entanto, se processam, na experiência moderna, em meio às transformações tecnológicas, que sugerem, como consequência, contínua revisão nos modelos teóricos da pesquisa em comunicação.

Em outras palavras, trata-se da dimensão comunicacional relacionada às manifestações culturais na experiência de modernização brasileira, incluindo a modernização midiática, que arrasta as práticas sociais de comunidades tradicionais para uma condição de cultura popular urbana. Considera-se a atualidade do pensamento comunicacional desenvolvido por Luiz Beltrão, localizando a contribuição de seus estudos, originários da década de 1960 e atualizados, nas primeiras décadas do século XXI, entre pesquisadores de sua obra (SCHMIDT, 2006; SCHMIDT, 2007; MELO, 2008; MACIEL; MELO; LIMA, 2011; MELO; FERNANDES, 2013) e na amplitude dos debates epistemológicos sobre o desenvolvimento da pesquisa em Comunicação (PRADO, 2002; LOPES, 2003; MARTINO; BERG; CRAIG, 2007; MELO, 1998; WEBER; BENTZ; HOHLFELDT, 2002).

Um dos debates em atualização sobre o campo da comunicação, no Brasil, refere-se à categoria mídia, cujo fundamento no processo comunicacional gerou um embate epistemológico polêmico na perspectiva folkcomunicacional, que tende a tornarse cada vez mais complexa por dois motivos:

1. Na perspectiva da folkcomunicação, a categoria mídia, não se resumindo à moderna e hegemônica mídia de massa e a qualquer suporte físico, demanda atenção às práticas culturais, não necessariamente midiatizadas. Essas práticas configuram-se como categoria empírica que compreende as práticas sociais como práticas de produção de sentido, no folclore e nas culturas populares, fazendo da questão comunicacional a busca por uma expressividade possível. Ou seja, a perspectiva folkcomunicacional considera a midiatização como processo, mas não se restringe à centralidade epistêmica da tecnologia midiática que se institui em modelos de pesquisa para os quais 
comunicação tornou-se sinônimo de modernização ou de relações necessariamente midiatizadas;

2. Ao mesmo tempo, a folkcomunicação apresenta-se contemporânea de uma experiência de modernização que força a emergência de constantes transformações tecnológicas, nas quais as tradições culturais ganham novas dimensões simbólicas, quando registradas e difundidas através de novas práticas midiáticas no âmbito de uma sociedade de consumo (BAUDRILLARD, 1995), em especial consumo de novas tecnologias digitais que vieram estruturalmente condicionando a mídia de massa a outros contornos operacionais e funcionais.

A perspectiva teórica da folkcomunicação se desenvolve nas Ciências da Comunicação, considerando as transformações tecnológicas advindas de uma experiência de modernização que se atualiza, em condições brasileiras, pela ampliação sempre crescente dos mercados consumidores de novas ferramentas midiáticas, impondo a necessidade de vigilância em nível epistemológico (LOPES, 2003) ao campo da comunicação. Essas condições históricas demandam a atualização da folkcomunicação como perspectiva teórica produzida no emergente ambiente acadêmico brasileiro na segunda metade do século XX. Como operação metodológica, pondera-se o lugar da folkcomunicação no quadro de referência mais amplo da modernização tecnológica como ideologia (PINTO, 2005), nos processos de consumo no capitalismo tardio (MANDEL, 1985) e na emergência da cultura das mídias (SANTAELLA, 1996) e da cibercultura (LÉVY, 1999; LEMOS; 2004) como modelos comunicacionais paradigmáticos a partir da década de 1990.

\section{Folkcomunicação: variáveis históricas e condições de emergência de um pensamento comunicacional}

Convém destacar a inovação dos estudos teóricos de Luiz Beltrão a partir do momento em que ele ensaia o conceito de folkcomunicação, ao ter como pano-de-fundo histórico as condições socioeconômicas, políticas e culturais vividas pela população brasileira na segunda metade do século XX. Beltrão, em sua experiência como jornalista, toma como ponto de partida de suas investigações teóricas as práticas folclóricas em sua 


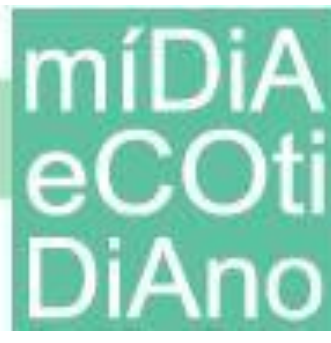

transição para a cultura popular e suas condições de marginalidade simbólica, tendo como lugar original de observação a realidade de Pernambuco, seu estado natal.

Numa entrevista a pesquisadores, realizada em 1986, Beltrão faz duas declarações, entre outras, que nos permitem inferir variáveis acadêmicas e políticas que constituem sua concepção de folkcomunicação. Na primeira declaração, sobre sua experiência como sindicalista, ele se declara Social Democrata, "um homem de ideias sociais democráticas", mas alertando aos entrevistadores para não confundirem com o antigo Partido Social Democrático (PSD) e nem como democrata social relacionado ao antigo Partido Democrático Social (PDS). Ele defende, diante das injustiças:

Do ponto de vista político, eu não posso deixar de considerar a profunda injustiça da sociedade atual, que beneficia uns demasiadamente e deixa a grande maioria em situação de penúria intelectual, cultural, social, econômica e moral. É necessário que haja uma abertura socializante. Atenção, é necessário uma abertura socializante, não socialista exatamente, mas socializante, a fim de que essas classes possam participar e ter os benefícios do desenvolvimento. Este é o meu pensamento político não extremado, pois não sou homem de extremos (BELTRÃO, 2004, p, 110).

A segunda declaração de Beltrão refere-se à leitura que ele faz da obra do etnógrafo e folclorista de formação marxista Edison Carneiro, "o único homem que percebeu que o folclore não era estático, o folclore não era uma coisa parada no tempo, mas uma coisa dinâmica" (BELTRÃO, 2004, p. 114). A partir dessa leitura, Beltrão verifica que "qualquer manifestação popular estava ligada ao povo, porque o povo não tinha meios, ele utilizava os meios que lhes davam" (BELTRÃO, 2004, p. 115).

Os meios construídos nas dinâmicas do folclore e do cotidiano são recursos culturais que as camadas populares usam para se entreter, se promover e se educar. Essas habilidades, desconstruindo a idealização do povo na imagem do brasileiro bonzinho, ganham em atualidade na "mensagem do bravo, do valente lutando capoeira às vezes com a navalha e a peixeira para defender as suas reivindicações" (BELTRÃO, 2004, p. 115).

No plano epistemológico, a contribuição dos estudos de Beltrão consistiu em ir além do funcionalismo sociológico como paradigma teórico nas Ciências Sociais que marcou o pensamento comunicacional num país industrializado e, então, em processo de 


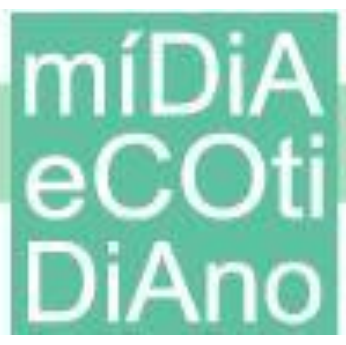

modernização como os EUA, para relativizar essa herança teórica e realocá-la na experiência singular de modernização, muito distinta, e evidentemente precária, da sociedade brasileira.

Para Luiz Beltrão, a relação entre folclore e cultura popular o inspirou a designar, por analogia, um modo dissidente de transmissão de notícias e expressão do pensamento e das reivindicações coletivas: "Folkcomunicação é, assim, o processo de intercâmbio de informações e manifestação de opiniões, idéias e atitudes da massa, através de agentes e meios ligados direta ou indiretamente ao folclore" (BELTRÃO, 2001, p. 79). No campo comunicacional, a folkcomunicação evidencia a paisagem cultural que se institui na relação, bastante evidente no Brasil, entre desigualdades econômicas, diferenças socioculturais e as constantes transformações tecnológicas e midiáticas.

Essas três variáveis históricas produzem desafios epistemológicos na medida em que desigualdades, diferenças e transformações, consideradas em sua simultaneidade, mas não necessariamente em movimentos sincrônicos, supõem barreiras quando se trata da relação entre produção/consumo de bens simbólicos e processos cognitivos como parte do processo de produção de sentido em comum que, ao menos em tese, caracteriza o que se entende por comunicação.

Dois momentos precisam ser considerados na abordagem da folkcomunicação: 1) as expressões populares se produzem na medida em que são mediadas e reinterpretadas a partir de sua relação, entre convergente e tensa, com a difusão da comunicação de massa como fenômeno sociotécnico no século XX (BELTRÃO, 1980, p. 27) e 2) a ênfase na manifestação artesanal, de difusão horizontal e interpessoal do agente comunicador, considera que mensagens são "elaboradas, codificadas e transmitidas em linguagens e canais familiares à audiência”. (BELTRÃO, 1980, p. 28)

Nesses dois momentos registra-se o processo de inovação de Luiz Beltrão na pesquisa em comunicação, cujos parâmetros teórico-metodológicos eram hegemonicamente fornecidos, na década de 1960, pela mass communication research (pesquisa em comunicação de massa) americana, produzida na perspectiva da comunicação como ciência do comportamento. Nos dias de hoje, com os debates epistemológicos, a noção de mídia na folkcomunicação se aproxima da concepção de artefatos da cultura como condição de expressão e veiculadoras de informação. 
Beltrão, ao atentar-se para a produção de sentido nas práticas sociais cotidianas, considera a potencialidade comunicacional a partir das manifestações folclóricas e da cultura popular. As angústias psicológicas da prática dos ex-votos no catolicismo popular, a crítica social explicitada na sátira política da malhação-do-judas, as táticas expressivas em linguagem sonora, oral e visual dos não-letrados, entre outras expressividades, sugerem que, nas culturas tradicionais e na sua difusa transição para o popular urbano, as expressões culturais constituem não o processo comunicacional eficiente, em termos sistêmicos ou na modernidade dos letrados, mas a busca de uma expressividade possível.

A expressividade possível torna-se uma demanda na medida em que os modernos modelos de comunicação - via linguagem verbal escrita/falada e uso de tecnologias midiáticas - não necessariamente constituem o cotidiano ou contemplam gratificações de produção e consumo de informações por parte de amplas faixas da população em suas diferenças de classe e distinções culturais. Saber usar as coisas e as instituições onde se nasce constitui um modo de se produzir a sobrevivência no que Agnes Heller designa por vida cotidiana (HELLER, 1997, p. 22).

A interface entre comunicação e cultura torna-se tênue na medida em que a abordagem da folkcomunicação coloca em questão a tipologia classificatória da categoria mídia, que compreende, de modo reducionista, os artefatos impressos e eletrônicos como fundamento do processo comunicacional que pressiona epistemologicamente o campo da comunicação a uma concepção enfaticamente modernizadora no plano do consumo tecnológico.

Historicamente, a centralidade midiática tem sido uma referência hegemônica nos estudos em comunicação, a partir da communication research como modelo teórico alçado à condição de paradigma científico no século XX. Mesmo estudos de abordagem crítica, via estudos da comunicação como ciência da linguagem ou como ciência crítica (LIMA, 2005), têm colaborado para a consolidação desse conceito de mídia relacionado enfaticamente, quando não apenas, à mídia como moderna ferramenta tecnológica.

Na modernização brasileira, marcada pela precariedade econômica, é preciso considerar os processos de transformação do ambiente sociotécnico no espaço urbano nacional. Nos processos de transformações socioeconômicas, políticas e culturais na virada de milênio, certamente que as culturas tradicionais, genericamente vinculadas às 


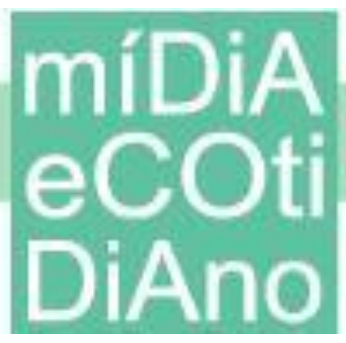

camadas pobres, em muito acentuou suas transformações em culturas populares urbanas, considerando principalmente as experiências históricas dos fluxos migratórios das áreas rurais para as cidades e o processo de modernização que se atualiza na sociedade brasileira. Nessa condição histórica evidenciam-se os usos da cultura como modos de expressão popular, até o ponto em que a cultura se torna a mediação onde se inventam processos de produção de sentido como processos de comunicação.

Nem letrado nem formal, nem culto nem erudito, o sistema da cultura popular dota-se de seus próprios meios de expressão (BELTRÃO, 2001). O ambiente cultural torna-se condição de expressão, a partir de distintos procedimentos de cognição e aprendizado na lida com variadas linguagens (musicais, gestuais, visuais etc.), que podem ser reapropriadas nos processos de consumo cotidianos de mídias industriais massivas ou no acesso, em geral rarefeito, aos ambientes eruditos.

Nessa perspectiva, o campo cultural ganha uma condição estruturante dos ambientes comunicacionais. A folkcomunicação, ao constituir-se tendo como foco as narrativas populares que medeiam a circulação das informações dos meios de massa e dos setores eruditos, concebe-se numa dinâmica socioeconômica e cultural em constante transformação, considerando a complexidade social no que se refere aos fluxos de informações e de produção de sentido.

\section{Transformações tecnológicas e usos populares das mídias digitais}

Na passagem de século XX ao século XXI, distintos grupos sociais ligados a setores do folclore e das culturas populares urbanas passaram a relacionar-se não mais apenas com as mensagens dos meios de comunicação de massa. Nos dias de hoje, passaram mais precisamente a fazer uso das novas tecnologias digitais de comunicação, constituindo, para além das categorias profissionais da comunicação social, diversas e difusas práticas midiáticas nos então emergentes modelos sociotécnicos da cultura das mídias, caracterizada pela "capacidade de trânsito da informação de uma mídia a outra" (SANTAELLA, 1996, p. 36), e da cibercultura, caracterizada pelas "mutações no universo digital após os anos 2000" (LÉVY, 1999, p. 21) e pela "lógica da apropriação tecnológica" (LEMOS, 2004, p. 238). 
Essas práticas midiáticas, nas transformações tecnológicas, vêm tornando ainda mais difuso o conceito de mídia e, como consequência, a comunicação como campo do saber, dadas as práticas de comunicação amadoras como afirmação de marcas de distinção no âmbito popular, nos termos do sociólogo Pierre Bourdieu (2004, p.109), evidenciando a categoria de usos midiáticos (GUSHIKEN, 2008), que argumenta as práticas de consumo como condição estruturante das práticas comunicacionais. O uso de novas tecnologias inclui, entre outras práticas sociais, a produção de audiovisual com que, de forma bastante evidente, indivíduos e grupos sociais ligados ao folclore e às culturas populares urbanas vêm construindo narrativas de si mesmos, reinventando modos de se autorrepresentar através de práticas midiáticas no cotidiano (BENJAMIN, 2007).

Um vídeo em suporte DVD, de modesta produção técnica, registra e divulga a música e a dança do Boi da Maioba, grupo folclórico que atua na região metropolitana de São Luís, no Maranhão. A produção do vídeo, com direção de fotografia aparentemente de apenas uma câmera e edição sem corte de imagens, indica a astúcia de "modos de fazer", em nada relacionado à estética da indústria do entretenimento ligada aos conglomerados produtores de audiovisual. O modesto vídeo, em sua caracterização caseira e amadora, torna-se, afirmativamente, uma ferramenta do grupo folclórico para registrar e divulgar suas próprias atividades culturais, deixando no campo audiovisual um registro possível de suas práticas.

Em Canindé, no Ceará, outro vídeo em DVD, também de caracterização caseira e amadora, apresenta registros sobre arquitetura das igrejas, procissões e outras manifestações de fé no catolicismo popular na cidade, que recebe romeiros do Ceará e de várias partes do país. O vídeo, com poucos cortes e edição linear, evidencia igualmente as condições da produção audiovisual no âmbito da religiosidade popular praticada no interior cearense.

Os usos de mídia digital e produção de vídeos caseiros tornaram-se possíveis com câmeras portáteis, à venda no comércio informal, o popular "camelô". Esses equipamentos tornaram-se de mais fácil acesso a um número crescente de consumidores das classes C e D. Os produtos audiovisuais do folguedo popular e da religiosidade católica, vendidos a preços acessíveis no comércio popular de São Luís e de Canindé, 


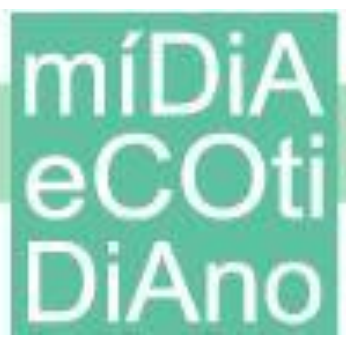

permitem registrar e divulgar, ainda que de modo precário, as práticas culturais relacionadas ao popular urbano em distintas localidades no país.

O uso de novas tecnologias digitais pelas camadas populares, no entanto, ainda tende a enfrentar, no imaginário social, o julgamento moralista do preconceito de classe de que aos trabalhadores, em geral, e aos mais pobres, de forma específica, caberia não mais que o sustento das necessidades básicas dos direitos sociais: alimentação, saúde, habitação e lazer. As práticas midiáticas das camadas populares, a partir do consumo de equipamentos audiovisuais, seriam uma espécie de excedente, no âmbito de um consumo supostamente supérfluo e em meio à precariedade socioeconômica.

Os índices de precariedade social no Brasil, registrados no século XX, persistem no século XXI, evidenciando ainda sua expansão numérica e quantitativa, principalmente nas periferias das cidades. Desemprego de jovens, nutrição apenas razoável, falta de escolas e habitação em favelas eram notificados no Brasil em pesquisas sociológicas já na década de 1970 (QUEIROZ, 1978). Nos dias de hoje, as periferias e demais áreas de baixa renda nas cidades brasileiras impõem um estilo de vida urbano marcado por índices de precariedade material, mas com a presença simultânea de tecnologias midiáticas de entretenimento, o que inclui antenas parabólicas, computadores com internet de banda larga, sistemas de TV a cabo, equipamentos de audiovisual os mais diversos, embora de acesso ainda muito restrito.

Entre a sofisticação tecnológica oriunda dos países desenvolvidos e a precariedade social brasileira, os usos midiáticos vêm redefinindo a existência simbólica através de experiências de produção de linguagem e narrativas de si, ao mesmo tempo em que constituem potencialmente a existência econômica e material em meio às constantes crises econômicas típicas de países em desenvolvimento (GUSHIKEN, 2008).

Entre euforia e ceticismo, as condições paradoxais de consumo de bens materiais condicionam a produção de bens simbólicos, considerados no mundo de hoje como recursos econômicos. No processo de consumo tecnológico, o uso dos dispositivos midiáticos redefine, numa condição de tática de sobrevivência, até mesmo a produção econômica de parte da população das periferias através do chamado trabalho imaterial (NEGRI; LAZZARATO, 2001), que necessariamente se relaciona com a produção, a circulação e o consumo de informações no atual estágio de modernização brasileira. 
Na urbanização incipiente e na emergência da mídia de massa, a cultura popular se resumia ou se confundia com as culturas tradicionais, cujas manifestações concentravam-se principalmente nas áreas rurais. A população rural no Brasil, a partir dos processos de modernização do país, migrou de forma massiva para as cidades, no processo simultâneo de urbanização ao longo do século XX. Boa parte dessa massa populacional vive no trânsito entre as zonas rurais e urbanas, reinventando nas cidades, não raro nas periferias, novas condições de existência econômica e simbólica.

A problemática urbanização brasileira constitui estruturalmente o campo simbólico das culturas populares urbanas, interface que incide na pesquisa em comunicação, na medida em que indica a dinâmica das transformações socioeconômicas e culturais operadas pela forçada experiência de modernização e ocidentalização dos costumes na contemporaneidade.

A experiência urbana, em sua dimensão social e econômica, sugere e demanda uma atualização do conceito de folkcomunicação como comunicação em sua relação com o folclore e, portanto, comunicação no âmbito das culturas populares em sua característica urbana. Convém anotar que a categoria cultura popular refere-se propriamente à noção de transformação (ORTIZ, 2006, p. 71), embora o folclore também já fosse considerado como processo dinâmico, relacionado diretamente às demandas de mobilidade social (CARNEIRO, 2008).

As nuances entre folclore e cultura popular, portanto, tornam-se relevantes na medida em que se testemunha o atravessamento do capitalismo na América Latina e as mudanças culturais processadas no Brasil em sua própria experiência de modernização. As constantes transformações da categoria do popular se referem especificamente aos dados culturais, mas deve-se considerar que as transformações culturais encontram-se ligadas, em diferentes intensidades, com as transformações socioeconômicas e políticas.

Nessa perspectiva, a folkcomunicação sugere repensar as culturas tradicionais em meio ao processo de consumo de tecnologias midiáticas no desenvolvimento do capitalismo. Se as categorias de folclore e de cultura popular tornam-se nuançadas pela distinção entre tradição e mudança, as categorias de mediações (MARTÍN-BARBERO, 1997), culturas híbridas (CANCLINI, 1998) e sincretismos (CANEVACCI, 1996) 
sugerem também a lida com as condições transitivas do campo cultural na contemporaneidade.

No Brasil, a tradição estudada pelos folcloristas, pelas Ciências Sociais, pelos Estudos Culturais e pela Comunicação se relaciona muito fortemente com as práticas sociais e culturais dos setores populares. Não por acaso, o popular se relaciona de modo muito próximo com a já conhecida condição de precariedade socioeconômica de amplas faixas da população brasileira.

Aponta-se, no início do século XXI, no Brasil, a emergência do que a sociologia do consumo vem chamando de identidade de classe média, na medida em que as classes C e D passaram a alterar o perfil socioeconômico da sociedade brasileira a partir do acesso a créditos financeiros, emitidos pelo sistema bancário internacional, e maior acesso a bens antes restritos às classes A e B. Telefones móveis (celulares), computadores e acesso à banda larga são itens que passaram a constar dos processos de consumo da classe média baixa (C) aos padrões de consumo da classe média alta. (SOUZA; LAMOUNIER, 2010, p. 43).

Sofisticação tecnológica e precariedade social configuram as condições históricas de produção, circulação e consumo de linguagens, mensagens e informações na abordagem da folkcomunicação, considerando-a uma original contribuição brasileira para as Ciências da Comunicação na segunda metade do século XX (MELO, 2004). Desigualdades sociais (do ponto de vista econômico) e diferenças culturais (do ponto de vista simbólico), em suas fricções históricas, ganham aquela condição em que o simbólico tende a direcionar o econômico a outras questões: a) considerar o consumo de tecnologias midiáticas como condição material de produção simbólica; e b) considerar o processo transitivo das memórias populares, na medida em que o popular se enreda ou é enredado pelo desenvolvimento do capitalismo em escala global.

\section{Folkcomunicação e consumo tecnológico no capitalismo tardio}

O consumo de novas tecnologias digitais hoje encontra-se em fase de expansão desde a virada de século em países de baixa renda per capita e de insistentes índices de pobreza como o Brasil, num processo evidente de avanço do capitalismo para regiões potencialmente identificadas como mercados consumidores. A expansão geográfica do 


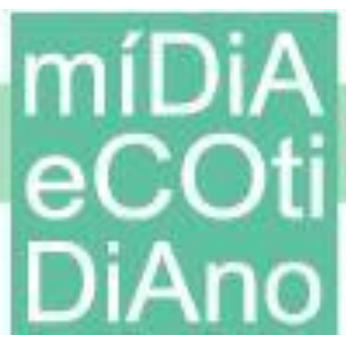

capitalismo, dos países desenvolvidos para os países em desenvolvimento, atualiza-se, portanto, num movimento político dos países centrais para os países enquadrados na periferia da produção econômica. Nessas condições históricas, os países de economia periférica se inserem no sistema capitalista a partir, principalmente, da segunda metade do século XX, na condição de reprodutores comerciais através de processos de consumo. Trata-se do momento histórico que o economista belga Ernest Mandel denomina capitalismo tardio (MANDEL, 1985).

$\mathrm{Na}$ medida em que a produção de informações tem relações diretas com o consumo de equipamentos digitais, o uso das novas tecnologias midiáticas atualiza a idéia pioneira da escola latino-americana da comunicação de que o polo ou campo da recepção demanda tornar-se simultaneamente fonte produtora de informações (GUSHIKEN, 2006) e também os modos como as práticas comunicacionais ganham nova dinâmica nas condições tecnológicas da cibercultura (SCHMIDT, 2007).

Essa nova condição de produção de informações ganha em atualidade na medida em que amplas faixas da população nos países em desenvolvimento passam a ter acesso a tecnologias destinadas, na abertura de novos mercados, a públicos em nichos de consumo muito específicos, como é o caso do mercado brasileiro. Trata-se do espraiamento da lógica do capital, em que a busca incessante de novos mercados força o próprio capitalismo a estender seu raio de ação, ampliando-se de forma contínua como sistema social (WALLERSTEIN, 2001).

Nas transformações tecnológicas do audiovisual, uma câmera filmadora portátil de uma marca japonesa, de atuação transnacional, era anunciada numa revista semanal brasileira, dirigida às classes A, B e C, oferecendo a possibilidade de três modelos, cada qual com seus apetrechos e sofisticações tecnológicas. O slogan - prática e fácil de usar - enfatizava os artifícios e as vantagens que os designers chamam de interface amigável nas constantes mutações tecnológicas em equipamentos de uso doméstico. $\mathrm{O}$ apelo mercadológico centrava-se no fato de o usuário, diante da novidade tecnológica sem mistérios para manuseio, fazer ajustes e regulagens na tela sensível ao toque. Entre os recursos técnicos, a câmera oferecia zoom óptico (aproximação de imagem em 40x com software embutido no equipamento); recurso técnico para fotografar e filmar ao mesmo tempo (dual rec), sistema desenvolvido para localizar o rosto das pessoas e fazer ajustes 
de vários parâmetros automáticos (face detection), microfone zoom (que ajusta o zoom do áudio ao zoom da lente), além de permitir a gravação de vídeo em formato DVD (VEJA, 2008).

Num outro segmento de mercado, a massificação do consumo de equipamentos digitais, câmeras de vídeo portáteis, embora menos sofisticadas em recursos tecnológicos, passaram a ser oferecidas também em programas de televendas em canais de TV aberta no Brasil $^{2}$ a um público consumidor em condições de pagar cerca de R $\$ 900 \mathrm{em} \mathrm{dez}$ prestações mensais de $\mathrm{R} \$ 49,90$ e outras quatro trimestrais de $\mathrm{R} \$ 98,00$. O investimento em tecnologia móvel, pagável em parcelas mensais no cartão de crédito ou através de boleto bancário, hoje em dia tornou os equipamentos midiáticos mais acessíveis às grandes massas populacionais que se tornam públicos consumidores, uma vez que, como dizia o filósofo francês Gilles Deleuze (1992, p. 224), somos não mais assalariados, mas sujeitos endividados na sociedade de controle.

O processo contínuo de massificação dos usos midiáticos se atualiza nas regiões regiões de alta renda per capita no planeta e também em cidades brasileiras que mal passam pela experiência de industrialização ou desenvolvimento da economia de serviços. No Brasil, o camelódromo é o espaço comercial onde tecnologias produzidas nos países industrializados passam a circular depois de sua reprodução em países de economia emergente. Câmeras de vídeo, câmeras fotográficas, tocadores de MP4 (e seus desdobramentos inovadores), tocadores de DVD portáteis, equipamentos de som, telefones celulares, CDs piratas: há uma forma de consumo de produtos tecnológicos que evidencia uma inclusão digital própria do capitalismo tardio, centrado na reinvenção constante dos processos de consumo em amplas regiões do planeta, mas que certamente transforma também os modos de produção e reprodução cultural através das práticas midiáticas.

$\mathrm{Na}$ história das teorias da comunicação, o processo de consumo de tecnologias digitais neste século XXI reforça a ideia de o receptor tornar-se produtor e gestor de

\footnotetext{
${ }^{2}$ Dados relativos a agosto de 2008, período em que as câmeras de vídeo portáteis tornaram-se mais acessíveis ao consumo popular, tendência que se acentuou em anos posteriores; em janeiro de 2013, câmeras de vídeo estavam presentes em aparelhos celulares vendidos a preços mais acessíveis no comércio formal e informal nas cidades brasileiras.
} 
informações, o que era uma utopia no paradigma, hoje em processo de desgaste e de ampla crise, da comunicação de massa como modelo hegemônico. Este debate se atualiza na medida em que, conforme os processos de consumo, as tecnologias digitais passam a fazer parte do cotidiano dos segmentos populares praticamente ao modo de quinquilharias incorporadas ao mais banal dia-a-dia da população.

As transformações tecnológicas sugerem reconsiderar e reavaliar a noção de impacto da mídia não apenas no comportamento, mas também nos modos de a massa populacional produzir e fazer circular bens culturais. Produção de sites e blogs na internet, documentários com produção afirmativamente amadora, veiculação de imagens de vídeos a partir de telefones celulares, a convergência cada vez mais evidente de internet com telefonia celular nas últimas décadas.

Estas são transformações nos usos midiáticos que incidem em novas virtualidades nas quais as culturas tradicionais e populares tendem a ganhar, de forma cada vez mais acentuada, diferentes formas de representação e, de modo mais preciso, autorrepresentação, o que altera a natureza da produção cultural e comunicacional. Nessas condições de atualização tecnológica, uma questão se apresenta: o consumo de tecnologias midiáticas supõe uma concepção de desenvolvimento socioeconômico numa perspectiva de modernização das práticas sociais, o que inclui a orientação para práticas de consumo.

Historicamente, consumo é uma categoria que ganhou relevância nos campos econômico e científico apenas após o fim da Segunda Guerra Mundial, numa hipotética situação de paz mundial e ambiente propício ao desenvolvimento de mercados transnacionais. Consumo, portanto, relaciona-se diretamente com os interesses na formação de mercados globais. Esta interface entre desenvolvimento e cidadania reflete a tensão relacionada às desigualdades econômicas, que dedutivamente incidem sobre as diferenças socioculturais.

A abordagem folkcomunicacional, portanto, enuncia um imaginário social que remete aos aspectos paradoxalmente críticos e lúdicos da cultura popular brasileira, num momento do desenvolvimento do capitalismo em que as expressões folclóricas e populares dotam-se de valor simbólico, mas também de valor econômico (o tornar-se mercadoria), na medida em que se enredam sistematicamente na sociedade de consumo. 
No entanto, ao invés de sugerir uma percepção cândida da realidade social, as manifestações culturais das camadas populares não raro têm enfatizado um imaginário de conflito, constituído nas tramas das linguagens que se reinventam nas práticas sociais e midiáticas.

Nas contradições do capitalismo, nota-se o seguinte aspecto: da cultura científica e tecnológica produzida nos países desenvolvidos passam a depender, em boa parte, as condições de reprodução midiática da cultura popular em países em desenvolvimento, como o Brasil. A cultura popular, e seu equivalente de precariedade socioeconômica, indica uma condição contemporânea: para além dessa perspectiva modernizadora, a cultura se reproduz nas mais adversas condições, de forma multilinear. A comunicação, ao contrário, torna-se refém do axioma técnico-midiático de uma experiência de modernização que tende a condicionar a veiculação e a visibilidade ou não das mais diversas formas culturais.

Na comunicação midiática, a condição tecnológica da produção e reprodução cultural pode ser percebida pelo menos em dois momentos históricos relevantes na virada de século XX ao XXI: 1) na comunicação de massa, quando a visibilidade social dependia do filtro organizador produzido pela racionalidade do agendamento midiático (agendasetting, como ficou conhecida a hipótese na pesquisa em comunicação de massa); e 2) mesmo no paradigma da cibercultura, que sugere um virtual declínio da comunicação de massa como modelo comunicacional hegemônico, o princípio de visibilidade e reprodução das mais distintas manifestações culturais passa, ainda nos dias de hoje, pelo registro e pela veiculação nos mais diversos suportes de mídias digitais e depende da construção de uma habilidade como prática social.

A folkcomunicação, na virtualidade de produzir interfaces cada vez mais intensas com práticas da cultura das mídias e da cibercultura, atualiza-se como modelo teórico que emerge no final da década de 1960 e se desenvolve até as primeiras décadas do século XXI, considerando a conflituosa experiência de modernização brasileira. Portanto, folkcomunicação enfatiza o valor simbólico da produção cultural e as táticas populares quando se trata de produzir e fazer circular informações de novas narrativas. 


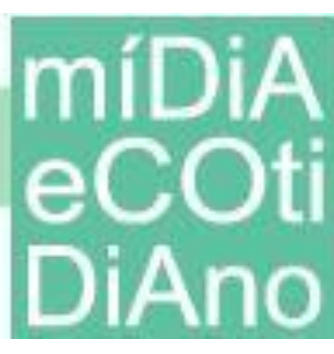

\section{Considerações finais}

A cultura contemporânea tem se configurado enfaticamente como uma cultura comunicacional. A comunicação de massa - que ascendeu como fenômeno técnico, econômico e social ao longo do século XX - suscitou uma pretensa universalidade na qual necessariamente desembocariam as representações de todas as formas culturais. Ou seja, todas as formas culturais tenderiam, nessa dimensão totalizante, a serem reduzidas à espessura da abordagem comunicacional de massa.

A midiatização das culturas em geral responde, portanto, a essa redução da cultura às práticas e aos modelos comunicacionais vigentes num determinado momento histórico. Assim, as práticas comunicacionais passaram a modular a visibilidade e a difusão - e em certa medida a existência simbólica - das mais variadas manifestações culturais, incluindo o folclore como manifestação tradicional e a cultura popular em sua noção de transformação social. A cultura, nesse sentido, torna-se refém das práticas comunicacionais, na medida em que uma certa noção de cultura só ganha evidência conforme se torna uma cultura midiatizada.

A relação entre comunicação e cultura sugere considerar pelo menos duas questões nas Ciências da Comunicação. Primeiro: o fato de que as práticas comunicacionais, nos dias de hoje, necessariamente precisam ser concebidas nos aparatos tecnológicos produzidos no processo de modernização do capitalismo como projeto globalizador. Segundo: se a moderna comunicação midiática se atualiza nos dispositivos tecnológicos desenvolvidos no modo de produção capitalista, a cultura, agora consequentemente e enfaticamente midiatizada, torna-se uma espécie de categoria dependente dos processos comunicacionais.

Assim, o campo comunicacional tende a acompanhar com mais intensidade a dinâmica das transformações técnicas e socioeconômicas do que o campo cultural compreendido num sentido mais amplo. Se o folclore, no mais das vezes, nas Ciências Sociais, é considerado resíduo cultural no bojo do intenso processo de modernização e ocidentalização do mundo, a folkcomunicação também se insinua como abordagem teórico-metodológica que se transforma no processo de modernização quando considera a contínua busca de produção de sentido como demanda social, seja ela midiatizada ou não. 
Aponta-se, portanto, o fato de que as manifestações folclóricas e populares, cada vez mais mediadas pelos usos das novas tecnologias digitais, evidenciam, no capitalismo contemporâneo, distintos modos como o antigo se confunde com o novo, a produção de sentido se confunde com a produção de valor (simbólico e econômico) e as mediações reinventam-se em meio às constantes inovações da tecnologia, até mesmo em situações de precariedade socioeconômica como é o caso da sociedade brasileira. Tais evidências possivelmente podem ser estendidas à realidade da América Latina e demais regiões geográficas, onde uma ideia de desenvolvimento, caracterizada pelos processos de ocidentalização e modernização, ainda sugere produção constante das desigualdades materiais e das diferenças simbólicas.

$\mathrm{Na}$ interface entre comunicação e cultura, talvez seja esta uma das características da contemporaneidade sugerida pela abordagem folkcomunicacional: os modos como as memórias do passado resistem ou insistem em se projetar para o futuro (o folclore ou o antigo passando à condição de cultura popular urbana e como novidade da modernização), a partir das tensões sociopolíticas e econômicas que constituem o tempo presente.

\section{Referências}

BAUDRILLARD, Jean. A sociedade de consumo. Lisboa: Edições 70, 1995.

BELTRÃO, Luiz. Folkcomunicação: a comunicação dos marginalizados. São Paulo: Cortez Editora, 1980.

BELTRÃO, Luiz. Folkcomunicação: teoria e metodologia. São Bernardo do Campo: Umesp, 2004.

BELTRÃO, Luiz. Folkcomunicação: um estudo dos agentes e dos meios populares de informação de fatos e expressão de idéias. Porto Alegre: Edipucrs, 2001.

BENJAMIN, Roberto. A folkcomunicação no contexto da sociedade midiatizada: A folkcomunicação e novas tecnologias. In: MELO, José Marques de; TRIGUEIRO, Osvaldo. (org.). Luiz Beltrão: pioneiro das Ciências da Comunicação no Brasil. João Pessoa: Editora UFPB, 2007, p. 227-232.

BOURDIEU, Pierre. A economia das trocas simbólicas. São Paulo: Editora Perspectiva, 2004.

CANCLINI, Nestor Garcia. Culturas híbridas: estratégias para entrar e sair da modernidade. Trad. Ana Regina Lessa; Heloísa Pezza Cintrão. São Paulo: Edusp, 1998. 
CANEVACCI, Massimo. Sincretismos: uma exploração das hibridações culturais. São Paulo: Studio Nobel, 1996.

CARNEIRO, Edison. A sabedoria popular. São Paulo: WMF Martins Fontes, 2008.

DELEUZE, Gilles. Conversações 1972-1990. São Paulo: Editora 34, 1992.

GUSHIKEN, Yuji. Dialogismo: emergência do pensamento latino-americano em comunicação. Comunicação, Mídia e Consumo, São Paulo, v. 3, n. 8, nov. 2006. DOI: http://dx.doi.org/10.18568/cmc.v3i8.81.

GUSHIKEN, Yuji. Usos midiáticos na constituição de circuitos culturais e comunicacionais populares urbanos. E-Compós, Brasília, v. 11, n. 1, 10 dez. 2008.

DOI: https://doi.org/10.30962/ec.244.

HELLER, Agnes. Sociología de la vida cotidiana. Barcelona: Ediciones Península, 1997.

LEMOS, André. Cibercultura: tecnologia e vida social na cultura contemporânea. Porto Alegre: Sulina, 2004.

LÉVY, Pierre. Cibercultura. São Paulo: Editora 34, 1999.

LIMA, Venicio Artur de. Mídia: teoria e política. São Paulo: Fundação Perseu Abramo, 2001.

LOPES, Maria Immacolata Vassalo de (org.). Epistemologia da Comunicação. São Paulo: Edições Loyola, 2003.

MACIEL, Betânia; MELO, José Marques de; LIMA, Maria Érica de Oliveira (org.).

Territórios da Folkcomunicação. Natal: Departamento de Comunicação Social, 2011.

MANDEL, Ernest. Capitalismo Tardio. São Paulo: Nova Cultural, 1985.

MARTIN-BARBERO, Jesús. Dos meios às mediações: comunicação, cultura e hegemonia. Trad. Ronald Polito e Sérgio Alcides. Rio de Janeiro: Editora da UFRJ, 1997.

MARTINO, Luis Claudio; BERGER, Charles. R.; CRAIG, Robert T. Teorias da comunicação: muitas ou poucas? Cotia: Ateliê Editorial, 2007.

MELO, José Marques de. Introdução à Folkcomunicação: Gênese, paradigmas e tendências. In: BELTRÃO, Luiz. Folkcomunicação: teoria e metodologia. São Bernardo do Campo: Umesp, 2004, p. 11-24.

MELO, José Marques de. Mídia e cultura popular: história, taxonomia e metodologia de pesquisa. São Paulo: Paulus, 2008.

MELO, José Marques de. O campo da Comunicação no Brasil. Petrópolis: Vozes, 2008.

MELO, José Marques de. Teoria da comunicação: paradigmas latino-americanos. Petrópolis: Vozes, 1998. 
MELO, José Marques de; FERNANDES, Guilherme (org.). Metamorfoses da folkcomunicação: antologia brasileira. São Paulo: Editae, 2013.

NEGRI, Antonio.; LAZARATTO, Maurizzio. Trabalho imaterial: formas de vida e produção de subjetividade. Rio de Janeiro: DP\&A, 2001.

ORTIZ, Renato. Cultura brasileira e identidade nacional. São Paulo: Brasiliense, 2006.

PINTO, Álvaro Vieira. O conceito de tecnologia Vol. 1. Rio de Janeiro: Contraponto. 2005.

PRADO, José Luis Aidar (org.). Crítica das práticas midiáticas: da sociedade de massa às ciberculturas. São Paulo: Hacker Editores, 2002.

QUEIROZ, Maria Isaura Pereira de. Cultura, sociedade rural e sociedade urbana no Brasil (Ensaios). São Paulo: LTC/Edusp, 1978.

SANTAELLA, Lúcia. Cultura das mídias. São Paulo: Experimento, 1996.

SCHMIDT, Cristina. A reprodutibilidade digital na folkcomunicação: A construção de novas linguagens ou o fim do popular. Comunicação \& Sociedade, ano 28, no. 47, $1^{\circ}$ sem, 2007.

SCHIMIDT, Cristina (org.). Folkcomunicação na Arena Global: avanços teóricos e metodológicos. São Paulo: Ductor, 2006.

SOUZA, Amauri de; LAMOUNIER, Bolivar. A classe média brasileira: ambições, valores e projetos de sociedade. Rio de Janeiro: Elsevier, 2010.

VEJA 2.058, ano 41, n. 17. 20, abril 2008.

WALLERSTEIN, Immnuel. Capitalismo histórico \& civilização capitalista. Trad. Renato Aguiar. Rio de Janeiro: Contraponto, 2001.

WEBER, Maria Helena; BENTZ, Ione.; HOHLFELDT, Antonio (org.). Tensões e objetos da pesquisa em comunicação. Porto Alegre: Sulina, 2002. 